\title{
Andreas Botthof
}

\section{Perspektiven der Minderjährigenadoption}

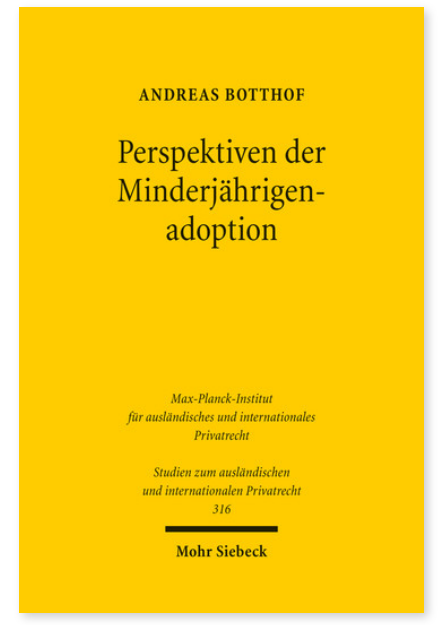

2014. XIV, 231 Seiten. StudIPR 316

ISBN 978-3-16-153484-3

DOI 10.1628/978-3-16-153484-3

eBook PDF 74,00€

ISBN 978-3-16-153458-4

fadengeheftete Broschur 74,00€
Jedes fürsorgebedürftige Kind soll in einer Familie aufwachsen. Diese sozialpolitische Zielsetzung wird vom geltenden deutschen Adoptionsrecht verfehlt. Es orientiert sich an der Vorstellung »leiblicher « Elternschaft und beharrt auf einer "Wiedergeburt« des Kindes in der Adoptivfamilie. Beide Konzepte sind nicht mehr zeitgemäß. Auf der Basis neuester sozialwissenschaftlicher und rechtsvergleichender Erkenntnisse entwirft Andreas Botthof eine gesetzgeberische Reaktion, die den gesellschaftlichen Veränderungen Rechnung trägt. Im Zentrum seiner Überlegungen steht das Kindeswohl. Es sollte auch den Mittelpunkt des internationalen Adoptionsrechts bilden. In Deutschland beweist eine Unzahl strittiger Gerichtsentscheidungen zum Status ausländischer Adoptionen, dass die juristische Praxis um einen einheitlichen Maßstab ringt. In diesem Spannungsfeld von Kindeswohl und Generalprävention liegt eine große Herausforderung für die Rechtspolitik. Auf der Grundlage einer differenzierten Auswahl von Fallbeispielen entwickelt der Autor überzeugende Handlungsoptionen.

Andreas Botthof Geboren 1986; Studium der Rechtswissenschaft in Marburg; seit 2011 Wissenschaftlicher Mitarbeiter am Lehrstuhl für Bürgerliches Recht an der Universität Marburg; 2014 Promotion; derzeit Rechtsreferendar am Kammergericht.

\section{Jetzt bestellen:}

https://mohrsiebeck.com/buch/perspektiven-der-minderjaehrigenadoption-9783161534843?no_cache=1 order@mohrsiebeck.com

Telefon: +49 (0)7071-923-17

Telefax: +49 (0)7071-51104 